\title{
Análise da Eficiência da Gestão de Custos do Processo de Produção de Arroz por pequenos e médios produtores de Limoeiro do Norte - CE
}

Geanne Benevides Sá Negreiros
Graduação em Ciências Contábeis pelo Centro Universitário Estácio do Ceará
Contadora Autônoma
Rua Eduardo Bezerra, 1414. Tauape. Fortaleza/CE. CEP: 60.130-271 E-mail: geannesa@hotmail.com

Rosângela Venâncio Nunes Mestrado em Logística e Pesquisa Operacional pela Universidade Federal do Ceará UFC Professora do Centro Universitário Estácio do Ceará Rua Sebastião de Abreu 177, apto 107 C. Maraponga. Fortaleza/CE. CEP: 60.710-830 E-mail: angelnuness@gmail.com

Charles Washington Costa de Assis Especialização em MBA em Gestão Financeira e Controladoria pela Faculdade Integrada do Ceará

Professor do Centro Universitário Estácio do Ceará Rua Sebastião de Abreu 177, apto 107 C. Maraponga. Fortaleza/CE. CEP: 60.710-830 E-mail: charles-cont@hotmail.com

Alexandra Alencar Siebra Mestrado em Administração e Controladoria pela Universidade Federal do Ceará - UFC Coordenadora do Curso de Ciências Contábeis do Centro Universitário Estácio do Ceará Av Santos Dumont 3665, apto 1201, Bloco A. Fortaleza/CE. CEP: 60.150-162 E-mail: alexandra.siebra@estacio.br

Rita de Cássia Fonseca Doutorado em andamento em Tecnologia pela Universidade Tecnológica Federal do Paraná - UTFPR Professora da Universidade Estadual do Centro Oeste -UNICENTRO Rua Presidente Zacarias de Goes, 875. Santa Cruz. Guarapuava/PR. CEP: 85.015-430 E-mail: ritadecfonseca@gmail.com

\section{RESUMO}

Diante de um cenário de alta competividade e busca de racionalização de recursos cada vez mais escassos, buscar a ciência é um dos desafios a serem vencidos pelas entidades. Considerando que a eficiência na gestão de custos é um dos indicadores de 
Análise da Eficiência da Gestão de Custos do Processo de Produção de Arroz por pequenos e
médios produtores de Limoeiro do Norte - CE

Geanne Benevides Sá Negreiros, Rosângela Venâncio Nunes Rosângela Venâncio Nunes, Charles Washington Costa de Assis, Alexandra Alencar Siebra, Rita de Cássia Fonseca

mais expressividade, a presente pesquisa, com abordagem descritiva, tem como finalidade analisar a eficiência da gestão de custos do processo produtivo de arroz por pequenos e médios produtores de Limoeiro do Norte, Ceará. Atualmente, nessa região, é possível ter duas safras ao ano, mesmo em período de seca, devido à tecnologia aplicada. Para a realização desta pesquisa, foi necessário um estudo com a elaboração de uma pesquisa de campo, que utilizou entrevistas diretas e semiestruturadas com dez agricultores da região analisada. Foi informado todo o ciclo produtivo do arroz com seus respectivos gastos. No decorrer do estudo, observou-se que a atividade agrícola é bastante complexa; os fatores ambientais influenciam de forma direta na produção, constatando-se que é imprescindível um controle de gastos com insumos. Na coleta de dados, foi verificado que mais de $40 \%$ dos custos dos produtores correspondem aos insumos. A mecanização trouxe maior eficiência ao processo, mas também promoveu diversidades comerciais relevantes. Apesar das maiores dificuldades enfrentadas pelo pequeno produtor, na análise de dados foi constatado que um deles foi mais eficiente que o médio produtor por hectare de área trabalhada. A safra, por hectare, de todos os produtores do estudo superou a produção das seguintes regiões: norte e sudeste.

Palavras-chave: Eficiência. Processo de produção de arroz. Custos de produção.

\section{Analysis of the Efficiency of the Management of Costs of Rice Production Process by small and medium producers of Limoeiro do Norte - CE.}

\section{ABSTRACT}

Faced with a scenario of high competitiveness and search for rationalization of increasingly scarce resources, seeking science is one of the challenges to be overcome by entities. Whereas the efficiency in cost management is one of the most expressiveness, the present research, with a descriptive approach, has as purpose of analyzing the efficiency of production process cost management of rice by small and medium producers in Limoeiro do Norte, Ceará. Currently, in this region, it is possible to have two harvests a year, drought, due to the technology applied. For the realization of this research, a study was necessary with the elaboration of a research of field, which used direct and semi-structured interviews with ten the region. The entire production cycle of the rice with their respective expenses. During the study, it was observed that the agricultural activity is quite complex; environmental factors influence directly in production, and it is control of expenditures with inputs. Mechanization brought greater efficiency to the process, but also promoted diversities relevant business. Despite the greatest difficulties faced by data was found that one of them was the average producer per hectare of area worked. The harvest, per hectare, of all the producers of the study exceeded the production of following regions: North and Southeast.

Keywords: Efficiency. Process of rice production. Costs of production. 
Análise da Eficiência da Gestão de Custos do Processo de Produção de Arroz por pequenos e médios produtores de Limoeiro do Norte - CE

Geanne Benevides Sá Negreiros, Rosângela Venâncio Nunes Rosângela Venâncio Nunes, Charles Washington Costa de Assis, Alexandra Alencar Siebra, Rita de Cássia Fonseca

\section{INTRODUÇÃO}

A atividade agrícola, responsável pela produção em grãos ou de alimentos a partir da exploração dos recursos naturais, é indispensável à alimentação do ser humano. Ao se considerar que as entidades, independentemente do setor a que pertençam, necessitam administrar diversos tipos de recursos que, por serem limitados, restringem suas atividades bem como a necessidade de obter resultados aos vários interessados, pressupõe a busca constante pela eficiência. Essa busca é caracterizada pelo aumento da produtividade dos recursos aplicados na produção de produtos e serviços, utilizando técnicas para produzir mais, aplicando o mínimo de recursos, o que representa uma tarefa imprescindível e constante em qualquer ramo da economia. Kiss (2015) afirma que, para melhorar a produtividade, introduziu uma nova linha de cultivo: a produção intensa de alimentos com o uso de equipamentos, insumos e sementes melhoradas. Assim surgiu uma nova maneira de produzir alimentos com mais eficiência.

Freitas (2014) afirma que o sistema agrícola brasileiro se distingue a partir do tamanho da área cultivada e do índice de produtividade alcançada, diante da complexidade do sistema rural brasileiro e da variedade de produtos primários.

O Brasil é um dos principais produtores e fornecedores de alimentos mundiais, possui terras férteis, extensas e clima propício para agricultura (Ministério da Agricultura, Pecuária e Abastecimento [MAPA] (2014). Fora do continente asiático, o Brasil é o maior produtor de arroz, onde a maior parte é consumida internamente e apenas 5\% da produção são exportados. Para Xavier e Abbade (2016), o arroz é um dos cereais mais consumidos no mundo. Segundo a Organização das Nações Unidas para a Alimentação e a Agricultura [FAO] (2014), este cereal é capaz de suprir 20\% da energia e $15 \%$ da proteína que um adulto necessita por dia, além de conter vitaminas, sais minerais, cálcio, ferro e fósforo.

O Departamento Nacional de Obras Contra as Secas [DNOCS] (2014) esclarece que o processo tecnológico na atividade agrícola surgiu em Limoeiro, 1989, com a implantação do Perímetro Irrigado de Morada Nova, sistema de cultivo irrigado. 

Análise da Eficiência da Gestão de Custos do Processo de Produção de Arroz por pequenos e
médios produtores de Limoeiro do Norte - CE

Geanne Benevides Sá Negreiros, Rosângela Venâncio Nunes Rosângela Venâncio Nunes, Charles Washington Costa de Assis, Alexandra Alencar Siebra, Rita de Cássia Fonseca

Esta nova forma de plantar modificou o cenário agrícola cearense, que passou a produzir mesmo em período de estiagem.

Para a Empresa Brasileira de Pesquisa Agropecuária [Embrapa] (2005), este sistema aborda todos os aspectos tecnológicos da cadeia produtiva na aplicação de insumos, no manejo integrado de pragas, no manejo adequado do solo e em outras formas de produção, com ações ambientalmente corretas.

Atualmente, a gestão da produção tem a finalidade de organizar a maneira com que as empresas fabricam produtos e/ou geram serviços usando da melhor maneira os recursos à disposição.

Para a Companhia Nacional de Abastecimento [Conab] (2010), o custo da produção agrícola é um instrumento de controle e gerenciamento das atividades produtivas e serve de apoio à tomada de decisão dos empreendedores.

Segundo Barros (2014), o produtor depende do mercado consumidor para o qual produz e raramente consegue colocar preço final no seu produto. Dessa forma, reduzir custos é um modo de aumentar a receita. Corroborando o estudo do referido autor, o produtor, ao identificar os custos de produção, deve observar os gastos mais expressivos e buscar uma forma de diminuí-los.

Tratando-se de atividade econômica, a agricultura está sujeita a maiores riscos, visto que utiliza como insumo fator incontrolável e de difícil previsibilidade como o clima. (Conab, 2014).

A administração eficiente dos custos de produção do cultivo de arroz é uma difícil tarefa para os arrozeiros, visto que esta gestão de custos é imprescindível para o agricultor obter maior receita e menores gastos em toda a fase de produção e venda do produto.

O presente artigo busca resolver a seguinte indagação: qual o nível de eficiência do processo produtivo de arroz realizado por pequenos e médios produtores localizados em Limoeiro do Norte, Ceará?

Visando atender ao questionamento proposto acima, o objetivo geral deste trabalho é analisar a eficiência do Processo Produtivo de Arroz realizado por pequenos

ABCustos, São Leopoldo: Associação Brasileira de Custos, v. 12, n. 2, p. 01-28, mai./ago. 2017 
Análise da Eficiência da Gestão de Custos do Processo de Produção de Arroz por pequenos e médios produtores de Limoeiro do Norte - CE

Geanne Benevides Sá Negreiros, Rosângela Venâncio Nunes Rosângela Venâncio Nunes, Charles Washington Costa de Assis, Alexandra Alencar Siebra, Rita de Cássia Fonseca

e médios produtores de Limoeiro do Norte, Ceará, no que se refere à gestão de seus custos de produção.

O presente estudo parte do pressuposto de que, ao analisar o processo de produção e os custos de produção de arroz de pequenos e médios produtores localizados na cidade de Limoeiro do Norte, seriam constatados diferentes níveis de eficiência, pois o médio produtor tenderia a ser mais eficiente que o pequeno produtor.

Para promover o desenvolvimento deste estudo e facilitar a compreensão do objeto de análise da pesquisa, foi realizada uma explanação bibliográfica por meio de um estudo teórico, tendo como referências autores das áreas de custos, gestão da produção e controladoria. Dentre eles, destacam-se: Padoveze (2005), Martins e Laugeni (2012), Da Silva e Venanzi (2013), Moreira (2011), Slack, Chambers e Johnston (2009), a fim de fundamentar o objetivo da pesquisa. Os autores citados foram relevantes como fonte de dados secundários.

\section{REVISÃO DE LITERATURA}

\subsection{Conceito de Eficiência}

A eficiência e a eficácia são duas palavras parecidas, mas de conceitos diferentes. Conforme Padoveze (2015), a eficiência está relacionada ao grau de utilização de recursos; já a eficácia está relacionada ao atingimento de resultados previamente fixados.

Para compreender melhor o que seria eficiência, reporta-se ao significado de um princípio da Constituição Federal do Brasil. Em 1998, foi acrescentado no art. 37, caput da Constituição Federal, pela emenda n. ${ }^{\circ}$ 19/98, o Princípio da Eficiência, apresentando os seguintes valores: economicidade, redução de desperdícios, qualidade, rapidez, produtividade e rendimento funcional.

Conforme Castro (2015, p.70), a eficiência é uma relação entre custos e benefícios, estando relacionada com a melhor utilização de recursos. Oliveira (2009) 
Análise da Eficiência da Gestão de Custos do Processo de Produção de Arroz por pequenos e médios produtores de Limoeiro do Norte - CE

Geanne Benevides Sá Negreiros, Rosângela Venâncio Nunes Rosângela Venâncio Nunes, Charles Washington Costa de Assis, Alexandra Alencar Siebra, Rita de Cássia Fonseca

afirma que eficiência é a otimização de recursos utilizados para a obtenção dos resultados esperados.

Assim, a eficiência diz respeito ao método, ao modo certo de fazer as coisas, relacionada entre volume produzido e recursos consumidos, conforme Equação 1 (Padoveze, 2005).

$$
\text { Eficiência }=\frac{\text { Entradas }}{\text { Saídas }}
$$

Segundo Silva e Venanzi (2013), a eficiência de uma fábrica pode ser vista em todos os setores da empresa. Na visão do mesmo autor, eficiência é a relação entre o resultado alcançado e o que foi consumido na fabricação.

Na percepção de Martins e Laugeni (2012), a conceituação de produtividade tem abrangência ampla. Uma delas, talvez a mais tradicional, é a que considera a produtividade como a relação entre o valor do produto e/ou serviço produzido e o custo dos insumos para produzi-lo.

Na compreensão de Moreira (2011), num sistema de produção, insumos são ajustados para fornecer uma saída; a produtividade está relacionada a maior ou menor utilização dos recursos nesse processo de produção.

Segundo Slack, Chambers e Johnston (2009), a administração da produção é a maneira pela qual as organizações produzem bens e serviços e, acima de tudo, um assunto que trata de problemas reais de produção. Os mesmos relatam que a função da produção nas empresas é a reunião de recursos destinados à produção de seus bens e serviços, satisfazendo as solicitações dos consumidores por meio da produção e entrega de produtos e serviços.

Para Padoveze (2005), a gestão operacional está relacionada com o seguinte ciclo: comprar, produzir e vender ou revender produtos ou serviços. É do entendimento do mesmo autor que: a gestão da utilização dos recursos necessários para o processo 
Análise da Eficiência da Gestão de Custos do Processo de Produção de Arroz por pequenos e médios produtores de Limoeiro do Norte - CE

Geanne Benevides Sá Negreiros, Rosângela Venâncio Nunes Rosângela Venâncio Nunes, Charles Washington Costa de Assis, Alexandra Alencar Siebra, Rita de Cássia Fonseca

de transformação, administração do sistema de transformação dos recursos e, finalmente, a direção do bem transformado aos clientes compõem a Gestão Operacional.

A partir do explanado, para competir no mercado é imprescindível uma gestão eficiente e capaz de cumprir todos os objetivos estabelecidos no planejamento, promovendo crescimento e desenvolvimento da atividade realizada.

\subsection{Gestão da Produção e Custos de Produção}

Segundo Martins e Laugeni (2012), as atividades desenvolvidas por uma empresa, visando atender seus objetivos de curto, médio e longo prazo, se interrelaciona, muitas vezes, de forma extremamente complexa, em que o objetivo da administração da produção é a gestão eficaz das atividades operacionais da empresa.

Cabe à gerência da base a tomada de decisões que levem a empresa a atingir seus objetivos primários (lucro) e secundários (oferecer empregos estáveis, ser inovadora, tornar-se empresa cidadã etc.), de uma forma racional que permita garantir a lucratividade e sustentar os objetivos secundários (Silva \&Venanzi, 2013).

Na percepção de Moreira (2009), a gestão da produção tem como foco central a fabricação de produtos de qualidade nos prazos estabelecidos no menor custo possível. Na concepção do autor citado, a gestão da produção apresenta os seguintes elementos: qualidade, prazo, custo, flexibilidade e confiabilidade.

Gestão da produção é, sobretudo, um assunto prático que trata de problemas reais, pois tudo o que é utilizado passa, de alguma maneira, por um processo produtivo, e organizar estes processos de maneira eficaz e eficiente é o objetivo da gestão da produção. (Slack, Chambers, \& Johnston, 2009).

Os custos de produção estão relacionados aos valores de bens e serviços utilizados na fabricação de outros bens e serviços. Conforme a Embrapa (2005), custos de produção constituem o valor gasto por cada item produzido. Para alcançar esse valor, basta somar materiais diretos, mão de obra e custo fixo; em seguida, dividir o resultado pelo volume de produção. 
Análise da Eficiência da Gestão de Custos do Processo de Produção de Arroz por pequenos e médios produtores de Limoeiro do Norte - CE

Geanne Benevides Sá Negreiros, Rosângela Venâncio Nunes Rosângela Venâncio Nunes, Charles Washington Costa de Assis, Alexandra Alencar Siebra, Rita de Cássia Fonseca

Em um mundo globalizado, competitivo, altamente dinâmico, a gestão de custos de produção amplamente eficiente é um dos maiores desafios para as empresas. Conhecer todos os gastos envolvidos no processo produtivo, aliado a uma perfeita gestão de custos, é fundamental para garantir a sobrevivência da entidade no mercado.

\subsection{Conceito de Pequeno e Médio Produtor Rural}

De acordo com o Instituto Brasileiro de Geografia e Estatística [IBGE] (2013), há 201,5 milhões de habitantes no Brasil e, deste total, 30,7 milhões residem na zona rural, ou seja, um percentual de $15,2 \%$ da população. Também foi levantado, pelo mesmo órgão, que $48,6 \%$ da população rural encontram-se na região nordeste, seguida do sudeste, com um percentual de $18,9 \%$.

A Secretaria de Estado de Agricultura, Pecuária e Abastecimento (2015) informou que as terras brasileiras estão divididas da seguinte forma: minifúndio, imóvel rural de área inferior a um módulo rural; pequena propriedade, que tem como limite de área um a quatro módulos fiscais; média propriedade, espaço compreendido entre $4 \mathrm{e}$ 15 módulos fiscais; e grande propriedade, superior a 15 módulos.

Segundo o estatuto do produtor rural, PLS 325/06, projeto de lei do Senado $n^{\circ}$ 352, de 2006: produtor rural é a pessoa física ou jurídica que explora a terra, com fins econômicos ou de subsistência, por meio da agricultura, da pecuária, da silvicultura, do extrativismo sustentável, além de atividades não agrícolas respeitadas a função social da terra. Conforme lei $n^{\circ} 11.428,2006$, pequeno produtor rural é aquele que, residindo na zona rural, detém a posse de gleba rural não superior a 50 hectares, explorando-a mediante o trabalho pessoal e de sua família, admitida a ajuda eventual de terceiros, bem como as posses coletivas de terra, considerando-se a fração individual não superior a 50 hectares, cuja renda bruta seja proveniente de atividades ou usos agrícolas, pecuários ou da silvicultura, ou do extrativismo rural, em $80 \%$ no mínimo.

De acordo com o Bacen, Manual de Crédito Rural (2008), produtor rural é pessoa física ou jurídica de acordo com a Receita Bruta Agropecuária Anual auferida ou, na falta dessa ou em caso de expansão da atividade, com a receita estimada (Res. 
Análise da Eficiência da Gestão de Custos do Processo de Produção de Arroz por pequenos e médios produtores de Limoeiro do Norte - CE

Geanne Benevides Sá Negreiros, Rosângela Venâncio Nunes Rosângela Venâncio Nunes, Charles Washington Costa de Assis, Alexandra Alencar Siebra, Rita de Cássia Fonseca

4.174, art. 1, Res 4.276, art. 5): pequeno produtor até $R \$ 360.000$; médio produtor acima de $R \$ 360.000$.

Consoante o CEBDS - Conselho Empresarial Brasileiro para Desenvolvimento Sustentável (2014), os pequenos e médios produtores da zona rural são classificados de acordo com a receita bruta anual: até 16 milhões, são considerados pequenos; entre 16 milhões até 90 milhões, são médios.

O arroz está entre os cereais mais consumidos no mundo, tendo um consumo médio mundial, per capita, de $58 \mathrm{~kg} / \mathrm{hab} . / \mathrm{ano}$ (FAO, 2014). Nesse cenário, o Brasil, que é considerado o 9ำ maior produtor mundial, com uma produção de 11,6 milhões de toneladas na safra de 2011-2012 (FAO, 2014), apresenta um consumo médio, per capita, de 12,3 milhões de toneladas (IBGE, 2014). Além disso, observa-se que a produção brasileira de arroz está fortemente concentrada na região Sul, onde o Rio Grande do Sul foi responsável por 66,6\% da produção de arroz no país em 2012 (IBGE, 2014).

De acordo com os dados do Instituto Brasileiro de Geografia e Estatística (IBGE, 2014), $90 \%$ da produção de arroz irrigado são produzidos na região sul, sendo que mais de $70 \%$ da produção brasileira ocorre no Rio Grande do Sul. O solo da região Sul é de várzea, o que contribui significativamente para o cultivo irrigado, já que se deve deixar o solo bem nivelado para que a água corra o mais uniforme possível (Embrapa, 2014). Apesar de o Brasil apresentar uma posição proeminente na produção de arroz, sua produtividade por hectare é bastante frágil. Em 2012, o Brasil ficou na 40aㅡ posição, apresentando um rendimento de 47.859,52 hectogramas por hectare plantado de arroz (FAO, 2014).

\subsection{Panorama Recente das Pesquisas Científicas sobre a Eficiência da Gestão de Custos do Processo de Produção por Pequenos e Médios Produtores}

De acordo com os dados do Instituto Brasileiro de Geografia e Estatística, em uma busca simples pelo portal SPELL, é possível perceber como a discussão sobre esse tema ainda é incipiente. Ao buscar o termo "eficiência da produção de arroz" em 

Análise da Eficiência da Gestão de Custos do Processo de Produção de Arroz por pequenos e
médios produtores de Limoeiro do Norte - CE

Geanne Benevides Sá Negreiros, Rosângela Venâncio Nunes Rosângela Venâncio Nunes, Charles Washington Costa de Assis, Alexandra Alencar Siebra, Rita de Cássia Fonseca

Resumos, filtrando a pesquisa em Artigos e Resumos de Teses ou Dissertações, de 2000 a 2016, foi possível encontrar apenas 02 pesquisas.

Antunes, Dias e Maehler (2012) estudaram o Processo de Inovação da Adoção do Sistema de Produção de Arroz Orgânico, vinculada ao Núcleo de Educação e Monitoramento Ambiental [NEMA]. Os resultados permitiram evidenciar a importância de incluir ONGs e empresas de pesquisa como atores estruturantes e o governo como criador de demandas específicas, bem como de analisar os recursos naturais como possíveis barreiras para a adoção do sistema de produção de arroz orgânico. Em relação à dinâmica das regras, os resultados fornecem um primeiro indicativo da evolução destas ao longo do processo de adoção de novos sistemas de produção.

Silveira, Antunes e Dias (2012) realizaram uma pesquisa sobre Inovação em sistemas de produção de arroz orgânico no Rio Grande do Sul. O estudo teve por objetivo identificar os grupos de produção orgânica no estado do Rio Grande do Sul e as inovações associadas a esses grupos. Quanto às inovações, os resultados do grupo dos produtores associados ao Núcleo de Educação e Monitoramento Ambiental estão em análise. Ainda assim, foi possível constatar que novas alternativas, mais sustentáveis, estão sendo adotadas pelos produtores e que esse tipo de cultivo vem crescendo nas últimas safras.

Em pesquisas realizadas na internet, foi possível identificar algumas pesquisas que relacionavam os fatores que influenciam a produtividade do arroz, como o intervalo hídrico (Beutler, Centurion, Silva, Roque, \& Ferraz, 2004), a fertilidade do solo (Lopes \& Guilherme, 2007), o uso de fertilizantes e resíduos industriais (Carvalho-Pupatto, Büll, Crusciol, Mauad, \& Silva 2003; Buzetti, Bazanini, Freitas, Andreotti, Arf, Sá, Meira, 2006), níveis de compactação do solo (Beutler et al., 2004), época de semeadura (Freitas, Silva, Mariot, Menezes, Anghinoni, Bredemeier, \& Vieira, 2008), genética das sementes (Breseghello, Rangel, \& Morais, 1999), intempéries e condições climáticas, dentre outros. Conforme Xavier e Abbade (2016), múltiplas formas podem ser delineadas de modo a desenvolver a produtividade agrícola do setor arrozeiro, dependendo das especificidades que os produtores enfrentam. 
Análise da Eficiência da Gestão de Custos do Processo de Produção de Arroz por pequenos e médios produtores de Limoeiro do Norte - CE

Geanne Benevides Sá Negreiros, Rosângela Venâncio Nunes Rosângela Venâncio Nunes, Charles Washington Costa de Assis, Alexandra Alencar Siebra, Rita de Cássia Fonseca

- Destarte, com as experiências das pesquisas anteriores sobre o tema, este estudo se diferencia primariamente no sentido de que focaliza a questão da eficiência da gestão de custos do processo de produção de arroz por pequenos e médios produtores.

- $\quad$ A próxima fase do estudo corresponde à metodologia aplicada. Esta etapa da pesquisa vai mostrar todos os procedimentos, métodos necessários para responder a questão formulada da pesquisa, ou seja, o caminho seguido e os instrumentos usados para alcançar o resultado do estudo.

\section{PROCEDIMENTOS METODOLÓGICOS}

Os procedimentos metodológicos utilizados neste estudo são apresentados conforme seu objeto de estudo, processo de coleta e análise de dados.

A presente pesquisa tem como objeto de estudo e limite de pesquisa a análise da eficiência da gestão de custos do processo de produção de arroz por pequenos e médios produtores de Limoeiro do Norte, Ceará. Utilizou-se, como período de análise, a safra do segundo semestre de 2014. Para dar qualidade ao estudo e aprofundar a matéria, realizaram-se visitas no local investigado com a finalidade de conhecer e observar o processo de produção do arroz. Em seguida, o trabalho descreve, explica e analisa todo o ciclo produtivo dos produtores analisados.

Conforme Santos, Campos, Coelho, Silva e Oliveira (2014), Limoeiro está situada entre dois grandes rios: Jaguaribe e Banabuiú, e apresenta uma população de 56.264 habitantes, em que mais de 10 mil pessoas residem na área rural, sendo que 900 famílias desempenham agricultura irrigada para sobreviver. Segundo Diário do Nordeste (2011), o perímetro está distribuído entre 324 pequenos produtores. Desses, 148 trabalham na fruticultura, e os demais agricultores, com os seguintes grãos: arroz, milho e feijão. 
Análise da Eficiência da Gestão de Custos do Processo de Produção de Arroz por pequenos e médios produtores de Limoeiro do Norte - CE

Geanne Benevides Sá Negreiros, Rosângela Venâncio Nunes Rosângela Venâncio Nunes, Charles Washington Costa de Assis, Alexandra Alencar Siebra, Rita de Cássia Fonseca

Conforme DNOCS (2009), esse munícipio faz parte do perímetro irrigado Jaguaribe-Apodi, e essa região apresenta um universo de 14 médios e 52 pequenos produtores proprietários de arroz.

Foi selecionada uma pequena amostra intencional de dez arrozeiros da região; para manter a confidencialidade, os mesmos estão identificados como: P1, P2, P3, P4, P5, P6, P7, P8, P9 e P10. Esta quantidade tem representatividade de $14 \%$ de pequenos produtores (P2, P3, P4, P5, P7, P8, P9, P10) e 15\% de médios produtores $(\mathrm{P} 1, \mathrm{P} 6)$ em relação à população mencionada pelo DNOCS.

Observando a classificação da lei 11.428/06, dos dez produtores pesquisados, oito (P2, P3, P4, P5, P7, P8, P9, P10) são considerados pequenos produtores, já que possuem até 50 hectares de área. Como foi verificado, há inexistência de lei definindo médio produtor rural, e, no estudo, foi detectado um produtor com 150 hectares e outro com 80 hectares. Para tanto, todos os produtores da região analisada foram classificados de acordo com o Manual de Crédito Rural do Banco Central do Brasil que os define pelo faturamento, da seguinte maneira: até $360.000,00$ - pequeno produtor; superior a $\mathrm{R} \$ 360.000,00$ até 1,6 milhão - médio produtor.

O estudo apresenta abordagem descritiva que, conforme Gil (2010), tem como objetivo a descrição de características de determinada população e podem ser elaboradas também com a finalidade de identificar possíveis relações entre variáveis.

Quanto ao processo de coleta de dados, a pesquisa utilizou-se, para a construção do referencial teórico, de fontes secundárias advindas da pesquisa bibliográfica. Para Severino (2007), a pesquisa bibliográfica é realizada a partir de documentos impressos, como livros e artigos. Visando responder a questão formulada, foi realizado, inicialmente, um estudo bibliográfico, teórico para embasar o resultado e tornar compreensível o objeto de estudo, baseado nos seguintes autores: Padoveze (2005), Martins e Laugeni (2012), Da Silva e Venanzi (2013), Moreira (2011) e Slack, Chambers, Johnston (2009). Essa fundamentação teórica foi essencial para dar suporte à pesquisa. 
Análise da Eficiência da Gestão de Custos do Processo de Produção de Arroz por pequenos e médios produtores de Limoeiro do Norte - CE

Geanne Benevides Sá Negreiros, Rosângela Venâncio Nunes Rosângela Venâncio Nunes, Charles Washington Costa de Assis, Alexandra Alencar Siebra, Rita de Cássia Fonseca

Para elaborar a parte aplicada, foi realizada a coleta de dados primários em uma pesquisa em campo, que esteve focada em descrever o processo produtivo de dez produtores de arroz da região do Baixo Jaguaribe, Limoeiro do Norte, analisar seus custos de produção e seu nível e eficiência. Todos os dados obtidos junto aos produtores da área investigada foram registrados, organizados e analisados, servindo os mesmos de apoio para responder a questão formulada.

O processo de coleta de dados foi basicamente dividido em duas fases: compreensão do processo produtivo do arroz e cálculo do custo de produção e da quantidade produzida de cada produtor.

Para realizar a contento todos os objetivos estabelecidos no início da pesquisa, foi necessário um estudo em campo de forma a aplicar a parte teórica à prática, para ampliar e aprofundar conhecimento.

Todos os dados levantados por meio do survey, conforme a concepção de cada agricultor no estudo em campo, foram registrados, organizados e analisados em planilhas e gráficos com a utilização dos programas Microsoft Excel e Microsoft Acess.

Para avaliar o nível e eficiência, seguiu-se, como metodologia, a definição de eficiência dada por Padoveze (2005), e a avaliação limitou-se aos resultados obtidos por hectare de área de cada agricultor. A base de comparação foi a obtida pelos produtores do estudo com o nível de eficiência dos produtores do Norte, Sul e Sudeste do Brasil.

Para isso, foram considerados todos os recursos utilizados no processo, desde o arrendamento do terreno, preparo do solo, mão de obra, sementes, adubação, herbicidas, manutenção da bomba, prestação de serviço, óleo, água e energia, transformados monetariamente e somados de forma individual.

Em seguida, o arroz foi medido pelo peso e avaliado em valor de venda no período em que a pesquisa foi realizada. Para finalizar, foi dividido o valor de venda da safra de arroz colhida no período pelos recursos introduzidos no processo de produção do arroz. O produtor que obtiver maior quociente é considerado o mais eficiente, obtendo-se a resposta ao quesito proposto. 
Análise da Eficiência da Gestão de Custos do Processo de Produção de Arroz por pequenos e médios produtores de Limoeiro do Norte - CE

Geanne Benevides Sá Negreiros, Rosângela Venâncio Nunes Rosângela Venâncio Nunes, Charles Washington Costa de Assis, Alexandra Alencar Siebra, Rita de Cássia Fonseca

\section{ANÁLISE DE RESULTADOS}

\subsection{Descrição do Ciclo Produtivo do Arrozeiro Cearense com seus Respectivos Custos}

Para Souza, Barbosa, Teixeira e Raimundo (2006), o Governo Federal vem implantando, desde 1970, perímetros públicos de irrigação no Ceará. Esse sistema de cultivo diferencia-se, basicamente, quanto à forma de preparo do solo, ao melhoramento genético das sementes e ao manejo inicial da água, por meio da tecnologia.

Pontes e Aragão (2013) afirmam que o sistema de irrigação em Limoeiro do Norte iniciou em 1989 e que esta tecnologia, aplicada no campo, proporcionou ao agricultor uma menor dependência da chuva e uma melhor utilização de recursos, produzindo mais em espaços menores.

De acordo com a Embrapa (2005), o cultivo de arroz irrigado, por submersão do solo, precisa de 2.000 litros de água $\left(2 \mathrm{~m}^{3}\right)$ para produzir $1.000 \mathrm{~g}$ de grãos com casca. A maior eficiência no controle de água está ligada à forma de adequação da superfície do solo.

Tejon (2015) aduz que a irrigação por gotejamento, sem alagar toda a área, como no sistema irrigado por alagamento, tem uma produção de $13.500 \mathrm{~kg}$ de arroz por hectare, quase o dobro da média brasileira e com apenas $50 \%$ da água $\left(5.750 \mathrm{~m}^{3}\right)$.

Outra forma de melhorar a eficiência no cultivo de arroz é controlando gastos. Os gastos com agroquímicos, mão de obra, frete e diesel do arrozeiro aumentaram de forma considerável. Gastos com herbicidas representam $10 \%$ do custo operacional total e aumentaram $41 \%$ em relação a 2013. A mão de obra teve alta de $9 \%$. O Diesel representa 10,5\% do COT e aumentou 8\% (Sperotto, 2013).

Ribeiro Filho (2013) expõe que a irrigação requer alto investimento em tecnologia para viabilizar a produção e agregar valor à produção.

No desenvolvimento da pesquisa, foram constatadas algumas alternativas de crédito em favor do produtor, como, por exemplo: o Governo Federal criou o PRONAF - 
Análise da Eficiência da Gestão de Custos do Processo de Produção de Arroz por pequenos e médios produtores de Limoeiro do Norte - CE

Geanne Benevides Sá Negreiros, Rosângela Venâncio Nunes Rosângela Venâncio Nunes, Charles Washington Costa de Assis, Alexandra Alencar Siebra, Rita de Cássia Fonseca

Programa Nacional de Fortalecimento da Agricultura Familiar, em 1995, e trouxe consigo algumas vantagens para o agricultor, como a concessão de crédito com encargos e condições adequadas à agricultura familiar.

O Banco Nacional de Desenvolvimento (2010) desenvolveu o PRONAMP Programa Nacional de Apoio ao Médio Produtor Rural, em que o produtor tem acesso a financiamento para aquisição de equipamentos, obras de irrigação, dentre outras concessões. Esse fundo tem prazo de até 8 anos e carência de até 3 anos para pagamento. Foi criado, em 2005, o Agroamigo, programa de microfinança rural do Banco do Nordeste, reconhecido internacionalmente, que concede crédito orientado e acompanhado de forma gradativa.

Conforme a Conab (2014), a maior produtividade brasileira de arroz encontra-se na região sul, com $7.460 \mathrm{kh} / \mathrm{ha}$, seguida da região norte, com $4.767 \mathrm{~kg} / \mathrm{ha}$.

Em suma, o cultivo de arroz é feito da seguinte forma:

- $\quad$ Primeiro o agricultor prepara o solo, uma espécie de limpeza do terreno;

- $\quad$ Em até 48 horas depois do preparo do solo, o agricultor planta as sementes pré-germinadas na terra pronta;

- Em torno de 20 dias depois da semeadura, a planta já está com aproximadamente $22 \mathrm{~cm}$ de altura, e é aplicado o herbicida;

- $\quad$ Por volta de 25 dias após aplicação de herbicida, ocorre a adubação;

- $\quad$ E quando o arroz estiver nascido, será feita à colheita, conforme Figura 1.

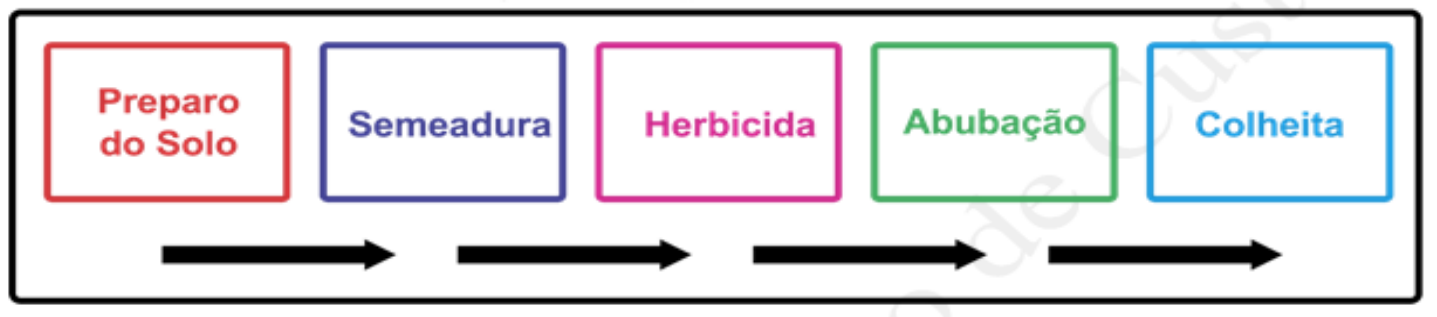

Figura 1. Ciclo produtivo do arroz

Fonte: Elaborado pelos autores (2015). 
Análise da Eficiência da Gestão de Custos do Processo de Produção de Arroz por pequenos e médios produtores de Limoeiro do Norte - CE

Geanne Benevides Sá Negreiros, Rosângela Venâncio Nunes Rosângela Venâncio Nunes, Charles Washington Costa de Assis, Alexandra Alencar Siebra, Rita de Cássia Fonseca

Todos os arrozeiros investigados declararam que o solo da região é muito fértil, rico em nutrientes, muito eficiente para o cultivo do arroz. Foi dito, pelo P1 e P4, que a maior parte das plantações de arroz em Limoeiro do Norte está dividida em quatro hectares, correspondentes a uma quadra, organizadas em oito marastas, ou seja, cada hectare apresenta duas marastas ou dois quadrados de terra cultivada. Também informaram que a duração do processo de arroz leva em torno de 100 dias. Todos os gastos envolvidos na produção de arroz dos dez agricultores estudados encontram-se na Tabela 1.

Tabela 1

Safra arroz irrigado - Limoeiro do Norte/CE - 2014.2 / custos por hectare

\begin{tabular}{|c|c|c|c|c|c|c|c|c|c|c|}
\hline Ciclo Arroz & P1 & $\mathbf{P 2}$ & P3 & P4 & P5 & P6 & P7 & P8 & P9 & P10 \\
\hline \multicolumn{11}{|l|}{ SOLO } \\
\hline Arrendamento & $R \$ 0,00$ & $\begin{array}{l}R \$ \\
500,00\end{array}$ & $\begin{array}{l}\mathrm{R} \$ \\
500,00\end{array}$ & \begin{tabular}{|l|}
$R \$$ \\
500,00 \\
\end{tabular} & \begin{tabular}{|l|}
$R \$$ \\
500,00 \\
\end{tabular} & $\mathrm{R} \$ 0,00$ & $R \$ 0,00$ & $\mathrm{R} \$ 0,00$ & $R \$ 0,00$ & $\mathrm{R} \$ 0,00$ \\
\hline - Rotativa & $R \$ 0,00$ & $\begin{array}{l}R \$ \\
265,00 \\
\end{array}$ & $\mathrm{R} \$ 0,00$ & \begin{tabular}{|l}
$R \$$ \\
240,00 \\
\end{tabular} & & \begin{tabular}{|l|}
$R \$$ \\
120,00 \\
\end{tabular} & \begin{tabular}{|l|}
$R \$$ \\
200,00 \\
\end{tabular} & $\begin{array}{l}\mathrm{R} \$ \\
300,00 \\
\end{array}$ & \begin{tabular}{|l|}
$R \$$ \\
300,00 \\
\end{tabular} & \begin{tabular}{|l|}
$\mathrm{R} \$$ \\
125,00 \\
\end{tabular} \\
\hline - Pranchão & $R \$ 0,00$ & $\begin{array}{l}\mathrm{R} \$ \\
50,00\end{array}$ & $\mathrm{R} \$ 0,00$ & $\begin{array}{l}\mathrm{R} \$ \\
60,00\end{array}$ & $\begin{array}{l}\mathrm{R} \$ \\
310,00\end{array}$ & $\begin{array}{l}R \$ \\
120,00 \\
\end{array}$ & $\begin{array}{l}R \$ \\
100,00\end{array}$ & $\begin{array}{l}R \$ \\
50,00 \\
\end{array}$ & \begin{tabular}{|l|}
$R \$$ \\
120,00 \\
\end{tabular} & $\begin{array}{l}R \$ \\
125,00 \\
\end{array}$ \\
\hline - Mão de obra & \begin{tabular}{|l|}
$\mathrm{R} \$$ \\
15,00 \\
\end{tabular} & $\mathrm{R} \$ 0,00$ & $\begin{array}{l}\mathrm{R} \$ \\
12,00\end{array}$ & $\mathrm{R} \$ 0,00$ & $\mathrm{R} \$ 0,00$ & $\mathrm{R} \$ 0,00$ & $R \$ 0,00$ & $R \$ 0,00$ & $\mathrm{R} \$ 0,00$ & $\mathrm{R} \$ 0,00$ \\
\hline - Óleo & \begin{tabular}{|l|}
$R \$$ \\
100,00 \\
\end{tabular} & $\mathrm{R} \$ 0,00$ & $\begin{array}{l}\mathrm{R} \$ \\
180,00 \\
\end{array}$ & $\mathrm{R} \$ 0,00$ & $\mathrm{R} \$ 0,00$ & $\mathrm{R} \$ 0,00$ & $\mathrm{R} \$ 0,00$ & $\mathrm{R} \$ 0,00$ & $R \$ 0,00$ & $R \$ 0,00$ \\
\hline - Manutenção & $\begin{array}{l}\mathrm{R} \$ \\
60,00 \\
\end{array}$ & $\mathrm{R} \$ 0,00$ & & $\mathrm{R} \$ 0,00$ & $R \$ 0,00$ & $R \$ 0,00$ & $R \$ 0,00$ & $R \$ 0,00$ & $\mathrm{R} \$ 0,00$ & $\mathrm{R} \$ 0,00$ \\
\hline - Sub-total & \begin{tabular}{|l|}
$R \$$ \\
175,00
\end{tabular} & $\begin{array}{l}\mathrm{R} \$ \\
\mathbf{8 1 5 , 0 0}\end{array}$ & $\begin{array}{l}\mathrm{R} \$ \\
692,00\end{array}$ & $\begin{array}{l}R \$ \\
800,00\end{array}$ & $\begin{array}{l}R \$ \\
810,00\end{array}$ & $\begin{array}{l}R \$ \\
240,00\end{array}$ & $\begin{array}{l}\mathrm{R} \$ \\
300,00\end{array}$ & $\begin{array}{l}\mathrm{R} \$ \\
350,00\end{array}$ & \begin{tabular}{|l|}
$R \$$ \\
420,00
\end{tabular} & \begin{tabular}{|l|}
$R \$$ \\
250,00
\end{tabular} \\
\hline \multicolumn{11}{|l|}{ FUNDAÇÃO } \\
\hline - Mão de obra & \begin{tabular}{|l|}
$R \$$ \\
15,00 \\
\end{tabular} & $\mathrm{R} \$ 0,00$ & $\mathrm{R} \$ 0,00$ & $\mathrm{R} \$ 0,00$ & $\mathrm{R} \$ 0,00$ & $\mathrm{R} \$ 0,00$ & $R \$ 0,00$ & $R \$ 0,00$ & $R \$ 0,00$ & \begin{tabular}{|l|}
$\mathrm{R} \$$ \\
35,00 \\
\end{tabular} \\
\hline - Óleo & \begin{tabular}{|l|}
$R \$$ \\
100,00 \\
\end{tabular} & $\mathrm{R} \$ 0,00$ & $\mathrm{R} \$ 0,00$ & $\mathrm{R} \$ 0,00$ & $\mathrm{R} \$ 0,00$ & $\mathrm{R} \$ 0,00$ & $R \$ 0,00$ & $\mathrm{R} \$ 0,00$ & $\mathrm{R} \$ 0,00$ & $R \$ 0,00$ \\
\hline - Adubo & $\begin{array}{l}\mathrm{R} \$ \\
245,00 \\
\end{array}$ & $\mathrm{R} \$ 0,00$ & $\mathrm{R} \$ 0,00$ & $\mathrm{R} \$ 0,00$ & $\mathrm{R} \$ 0,00$ & $\mathrm{R} \$ 0,00$ & $R \$ 0,00$ & $R \$ 0,00$ & $\mathrm{R} \$ 0,00$ & $\begin{array}{l}\mathrm{R} \$ \\
360,00 \\
\end{array}$ \\
\hline - Sub-total & \begin{tabular}{|l|}
$R \$$ \\
360,00 \\
\end{tabular} & $\mathrm{R} \$ 0,00$ & $\mathrm{R} \$ 0,00$ & $\mathrm{R} \$ 0,00$ & $\mathrm{R} \$ 0,00$ & $\mathrm{R} \$ 0,00$ & $R \$ 0,00$ & $R \$ 0,00$ & $\mathrm{R} \$ 0,00$ & \begin{tabular}{|l}
$\mathrm{R} \$$ \\
395,00 \\
\end{tabular} \\
\hline \multicolumn{11}{|l|}{ PLANTIO } \\
\hline - Semente & \begin{tabular}{|l|}
$R \$$ \\
200,00
\end{tabular} & $\begin{array}{l}\mathrm{R} \$ \\
250,00\end{array}$ & $\begin{array}{l}R \$ \\
200,00\end{array}$ & \begin{tabular}{|l}
$R \$$ \\
200,00
\end{tabular} & $\begin{array}{l}R \$ \\
275,00\end{array}$ & \begin{tabular}{|l}
$R \$$ \\
200,00
\end{tabular} & \begin{tabular}{|l}
$R \$$ \\
200,00
\end{tabular} & $\begin{array}{l}R \$ \\
200,00\end{array}$ & \begin{tabular}{|l|}
$R \$$ \\
200,00
\end{tabular} & \begin{tabular}{|l|}
$R \$$ \\
200,00
\end{tabular} \\
\hline - Aplicação & \begin{tabular}{|l|}
$R \$$ \\
50,00 \\
\end{tabular} & $\begin{array}{l}\mathrm{R} \$ \\
60,00 \\
\end{array}$ & $\begin{array}{l}\mathrm{R} \$ \\
60,00 \\
\end{array}$ & $\begin{array}{l}\mathrm{R} \$ \\
60,00 \\
\end{array}$ & $\begin{array}{l}\mathrm{R} \$ \\
25,00 \\
\end{array}$ & $\begin{array}{l}\mathrm{R} \$ \\
75,00 \\
\end{array}$ & $\begin{array}{l}\mathrm{R} \$ \\
30,00 \\
\end{array}$ & $\begin{array}{l}\mathrm{R} \$ \\
30,00 \\
\end{array}$ & \begin{tabular}{|l|}
$\mathrm{R} \$$ \\
30,00 \\
\end{tabular} & \begin{tabular}{|l}
$\mathrm{R} \$$ \\
30,00 \\
\end{tabular} \\
\hline - Subtotal & \begin{tabular}{|l|}
$R \$$ \\
250,00 \\
\end{tabular} & $\begin{array}{l}R \$ \\
310,00\end{array}$ & $\begin{array}{l}R \$ \\
260,00\end{array}$ & \begin{tabular}{|l|}
$R \$$ \\
260,00 \\
\end{tabular} & $\begin{array}{l}R \$ \\
300,00\end{array}$ & \begin{tabular}{|l}
$R \$$ \\
275,00
\end{tabular} & \begin{tabular}{|l|}
$R \$$ \\
230,00 \\
\end{tabular} & \begin{tabular}{|l}
$R \$$ \\
230,00
\end{tabular} & \begin{tabular}{|l|}
$R \$$ \\
230,00 \\
\end{tabular} & \begin{tabular}{|l|}
$R \$$ \\
230,00 \\
\end{tabular} \\
\hline \multicolumn{11}{|l|}{ HERBICIDA } \\
\hline - Veneno & \begin{tabular}{|l|}
$R \$$ \\
140,00 \\
\end{tabular} & $\begin{array}{l}R \$ \\
121,42\end{array}$ & $\begin{array}{l}R \$ \\
191,50\end{array}$ & $\begin{array}{l}R \$ \\
200,00\end{array}$ & $\begin{array}{l}R \$ \\
175,00\end{array}$ & $\begin{array}{l}R \$ \\
178,00\end{array}$ & $\begin{array}{l}R \$ \\
160,00\end{array}$ & $\begin{array}{l}R \$ \\
130,00\end{array}$ & \begin{tabular}{|l|}
$R \$$ \\
260,00
\end{tabular} & \begin{tabular}{|l|}
$R \$$ \\
120,00 \\
\end{tabular} \\
\hline
\end{tabular}


Análise da Eficiência da Gestão de Custos do Processo de Produção de Arroz por pequenos e
médios produtores de Limoeiro do Norte - CE

Geanne Benevides Sá Negreiros, Rosângela Venâncio Nunes Rosângela Venâncio Nunes, Charles Washington Costa de Assis, Alexandra Alencar Siebra, Rita de Cássia Fonseca

\begin{tabular}{|c|c|c|c|c|c|c|c|c|c|c|}
\hline - Aplicação & \begin{tabular}{|l|}
$R \$$ \\
50,00
\end{tabular} & $\begin{array}{l}\mathrm{R} \$ \\
60,00\end{array}$ & $\begin{array}{l}\mathrm{R} \$ \\
50,00\end{array}$ & \begin{tabular}{|l}
$R \$$ \\
60,00
\end{tabular} & $\begin{array}{l}R \$ \\
40,00\end{array}$ & $\begin{array}{l}\mathrm{R} \$ \\
60,00\end{array}$ & $\begin{array}{l}\mathrm{R} \$ \\
35,00\end{array}$ & $\begin{array}{l}\mathrm{R} \$ \\
35,00\end{array}$ & $\begin{array}{l}\mathrm{R} \$ \\
35,00\end{array}$ & $\begin{array}{l}\mathrm{R} \$ \\
35,00\end{array}$ \\
\hline - Subtotal & \begin{tabular}{|l|}
$R \$$ \\
190,00 \\
\end{tabular} & \begin{tabular}{|l|}
$\mathrm{R} \$$ \\
181,42 \\
\end{tabular} & \begin{tabular}{|l}
$\mathrm{R} \$$ \\
241,50 \\
\end{tabular} & \begin{tabular}{|l|}
$\mathrm{R} \$$ \\
260,00 \\
\end{tabular} & \begin{tabular}{|l|}
$\mathrm{R} \$$ \\
215,00 \\
\end{tabular} & \begin{tabular}{|l|}
$\mathrm{R} \$$ \\
238,00 \\
\end{tabular} & \begin{tabular}{|l}
$R \$$ \\
195,00 \\
\end{tabular} & \begin{tabular}{|l}
$R \$$ \\
165,00 \\
\end{tabular} & \begin{tabular}{|l}
$R \$$ \\
295,00 \\
\end{tabular} & \begin{tabular}{|l}
$R \$$ \\
155,00 \\
\end{tabular} \\
\hline \multicolumn{11}{|l|}{ ADUBAÇÃO } \\
\hline - Ureia & \begin{tabular}{|l}
$R \$$ \\
260,00 \\
\end{tabular} & \begin{tabular}{|l|}
$R \$$ \\
176,00 \\
\end{tabular} & \begin{tabular}{|l}
$\mathrm{R} \$$ \\
225,00 \\
\end{tabular} & \begin{tabular}{|l}
$\mathrm{R} \$$ \\
200,00 \\
\end{tabular} & $\begin{array}{l}\mathrm{R} \$ \\
300,00 \\
\end{array}$ & $\begin{array}{ll}R \$ \\
250,00 \\
\end{array}$ & $\begin{array}{l}\mathrm{R} \$ \\
258,00 \\
\end{array}$ & $\begin{array}{l}R \$ \\
240,00 \\
\end{array}$ & $\begin{array}{l}\mathrm{R} \$ \\
252,00 \\
\end{array}$ & $\begin{array}{l}R \$ \\
270,00 \\
\end{array}$ \\
\hline - Nitrogênio & \begin{tabular}{|l|}
$R \$$ \\
260,00
\end{tabular} & $\begin{array}{l}\mathrm{R} \$ \\
176,00\end{array}$ & $\begin{array}{l}\mathrm{R} \$ \\
225,00\end{array}$ & $\begin{array}{l}\mathrm{R} \$ \\
200,00\end{array}$ & $\begin{array}{l}\mathrm{R} \$ \\
300,00\end{array}$ & $\begin{array}{l}R \$ \\
150,00\end{array}$ & $\begin{array}{l}\mathrm{R} \$ \\
258,00\end{array}$ & $\begin{array}{l}\mathrm{R} \$ \\
240,00\end{array}$ & $\mathrm{R} \$ 252$ & $\begin{array}{l}\mathrm{R} \$ \\
270,00\end{array}$ \\
\hline - Foliar & $\begin{array}{l}R \$ \\
110,00 \\
\end{array}$ & $R \$ 0,00$ & $R \$ 0,00$ & $R \$ 0,00$ & $R \$ 0,00$ & $R \$ 0,00$ & $R \$ 0,00$ & $\begin{array}{l}R \$ \\
240,00 \\
\end{array}$ & $\begin{array}{l}\mathrm{R} \$ \\
252,00 \\
\end{array}$ & $R \$ 0,00$ \\
\hline - Aplicação & \begin{tabular}{|l|}
$R \$$ \\
150,00
\end{tabular} & \begin{tabular}{|l|}
$R \$$ \\
160,00
\end{tabular} & \begin{tabular}{|l|}
$R \$$ \\
120,00
\end{tabular} & \begin{tabular}{|l|}
$\mathrm{R} \$$ \\
160,00
\end{tabular} & \begin{tabular}{|l|}
$\mathrm{R} \$$ \\
60,00
\end{tabular} & \begin{tabular}{|l|}
$R \$$ \\
60,00
\end{tabular} & \begin{tabular}{|l|}
$R \$$ \\
60,00
\end{tabular} & \begin{tabular}{|l|}
$\mathrm{R} \$$ \\
90,00
\end{tabular} & \begin{tabular}{|l|}
$R \$$ \\
90,00
\end{tabular} & \begin{tabular}{|l|}
$R \$$ \\
40,00
\end{tabular} \\
\hline Subtotal & \begin{tabular}{|l}
$\mathrm{R} \$$ \\
780,00 \\
\end{tabular} & $\begin{array}{l}\mathrm{R} \$ \\
512,00 \\
\end{array}$ & $\begin{array}{l}\mathrm{R} \$ \\
570,00 \\
\end{array}$ & \begin{tabular}{|l|}
$\mathrm{R} \$$ \\
560,00 \\
\end{tabular} & $\begin{array}{l}\mathrm{R} \$ \\
760,00 \\
\end{array}$ & \begin{tabular}{|l|}
$R \$$ \\
460,00 \\
\end{tabular} & $\begin{array}{l}R \$ \\
576,00 \\
\end{array}$ & \begin{tabular}{|l}
$R \$$ \\
810,00 \\
\end{tabular} & $\begin{array}{l}\mathrm{R} \$ \\
846,00 \\
\end{array}$ & $\begin{array}{l}R \$ \\
580,00 \\
\end{array}$ \\
\hline ENERGIA & \begin{tabular}{|l|}
$\mathrm{R} \$$ \\
220,00
\end{tabular} & $\begin{array}{l}\mathrm{R} \$ \\
90,90\end{array}$ & \begin{tabular}{|l|}
$R \$$ \\
136,00
\end{tabular} & $R \$ 0,00$ & $\begin{array}{l}R \$ \\
93,75\end{array}$ & \begin{tabular}{|l}
$\mathrm{R} \$$ \\
203,00
\end{tabular} & $\mathrm{R} \$ 0,00$ & $\mathrm{R} \$ 0,00$ & $R \$ 0,00$ & $\mathrm{R} \$ 0,00$ \\
\hline ÁGUA & $R \$ 0,00$ & $R \$ 0,00$ & $R \$ 0,00$ & $\begin{array}{l}\mathrm{R} \$ \\
220,00 \\
\end{array}$ & $R \$ 0,00$ & $R \$ 0,00$ & $\begin{array}{l}\mathrm{R} \$ \\
220,00 \\
\end{array}$ & $\begin{array}{l}\mathrm{R} \$ \\
230,00 \\
\end{array}$ & $\begin{array}{l}\mathrm{R} \$ \\
220,00 \\
\end{array}$ & $\begin{array}{l}\mathrm{R} \$ \\
220,00 \\
\end{array}$ \\
\hline \multicolumn{11}{|l|}{ COLHEITA } \\
\hline Terceirização & $R \$ 0,00$ & \begin{tabular}{|l|}
$\mathrm{R} \$$ \\
715,00 \\
\end{tabular} & \begin{tabular}{|l|}
$\mathrm{R} \$$ \\
737,00 \\
\end{tabular} & \begin{tabular}{|l|}
$\mathrm{R} \$$ \\
487,50 \\
\end{tabular} & \begin{tabular}{|l|}
$\mathrm{R} \$$ \\
462,00 \\
\end{tabular} & \begin{tabular}{|l|}
$R \$$ \\
500,50 \\
\end{tabular} & $\begin{array}{l}R \$ \\
412,50 \\
\end{array}$ & \begin{tabular}{|l}
$\mathrm{R} \$$ \\
487,50 \\
\end{tabular} & $\begin{array}{l}R \$ \\
525,00 \\
\end{array}$ & $\begin{array}{l}\mathrm{R} \$ \\
520,00 \\
\end{array}$ \\
\hline - Mão de obra & \begin{tabular}{|l|}
$R \$$ \\
15,00 \\
\end{tabular} & $\mathrm{R} \$ 0,00$ & $R \$ 0,00$ & $R \$ 0,00$ & $R \$ 0,00$ & $\mathrm{R} \$ 0,00$ & $R \$ 0,00$ & $R \$ 0,00$ & $\mathrm{R} \$ 0,00$ & $\mathrm{R} \$ 0,00$ \\
\hline - Óleo & \begin{tabular}{|l|}
$R \$$ \\
55,00
\end{tabular} & $R \$ 0,00$ & $R \$ 0,00$ & $R \$ 0,00$ & $R \$ 0,00$ & $R \$ 0,00$ & $\mathrm{R} \$ 0,00$ & $\mathrm{R} \$ 0,00$ & $\mathrm{R} \$ 0,00$ & $\mathrm{R} \$ 0,00$ \\
\hline - Subtotal & \begin{tabular}{|l|}
$\mathbf{R} \$$ \\
70,00 \\
\end{tabular} & $\begin{array}{l}\mathrm{R} \$ \\
715,00 \\
\end{array}$ & \begin{tabular}{|l|}
$\mathbf{R} \$$ \\
737,00 \\
\end{tabular} & \begin{tabular}{|l|}
$\mathrm{R} \$$ \\
487,50 \\
\end{tabular} & \begin{tabular}{|l|}
$R \$$ \\
462,00 \\
\end{tabular} & \begin{tabular}{|l|}
$R \$$ \\
500,50 \\
\end{tabular} & $\begin{array}{l}R \$ \\
412,50 \\
\end{array}$ & $\begin{array}{l}R \$ \\
487,50 \\
\end{array}$ & $\begin{array}{l}R \$ \\
525,00 \\
\end{array}$ & $\begin{array}{l}\mathrm{R} \$ \\
520,00 \\
\end{array}$ \\
\hline $\begin{array}{l}\text { CUSTO } \\
\text { TOTAL }\end{array}$ & \begin{tabular}{|l|}
$R \$$ \\
$2.045,00$ \\
\end{tabular} & \begin{tabular}{|l|}
$\mathrm{R} \$$ \\
$2.624,32$ \\
\end{tabular} & \begin{tabular}{|l|}
$\mathrm{R} \$$ \\
$2.636,50$ \\
\end{tabular} & \begin{tabular}{|l|}
$\mathrm{R} \$$ \\
$2.587,50$ \\
\end{tabular} & \begin{tabular}{|l|}
$R \$$ \\
$2.640,75$ \\
\end{tabular} & \begin{tabular}{|l|}
$R \$$ \\
$1.916,50$ \\
\end{tabular} & \begin{tabular}{|l|}
$R \$$ \\
$1.933,50$ \\
\end{tabular} & \begin{tabular}{|l|}
$R \$$ \\
$2.272,50$ \\
\end{tabular} & \begin{tabular}{|l|}
$\mathrm{R} \$$ \\
$2.536,00$
\end{tabular} & \begin{tabular}{|l|}
$R \$$ \\
$2.350,00$ \\
\end{tabular} \\
\hline
\end{tabular}

Nota. Fonte: Elaborado pelos autores (2015)

\subsection{Análise dos resultados obtidos pela Safra do segundo semestre de 2014}

A Figura 2 evidencia a produção da safra 2014.2 dos produtores pesquisados e da produção brasileira de arroz, por região e por hectare. Avaliando a safra alcançada, a diferença entre a maior e a menor colheita é de, no mínimo, 20\%. P1 e P9, médio e pequeno produtor produziram a mesma quantidade de arroz: $7.000 \mathrm{~kg}$ cada, por hectare. Logo, é possível um pequeno produtor produzir mais que um médio produtor, num mesmo espaço de terra e com menos recursos disponíveis. É mais fácil controlar um espaço menor do que uma área maior, de acordo com P9. 
Análise da Eficiência da Gestão de Custos do Processo de Produção de Arroz por pequenos e médios produtores de Limoeiro do Norte - CE

Geanne Benevides Sá Negreiros, Rosângela Venâncio Nunes Rosângela Venâncio Nunes, Charles Washington Costa de Assis, Alexandra Alencar Siebra, Rita de Cássia Fonseca
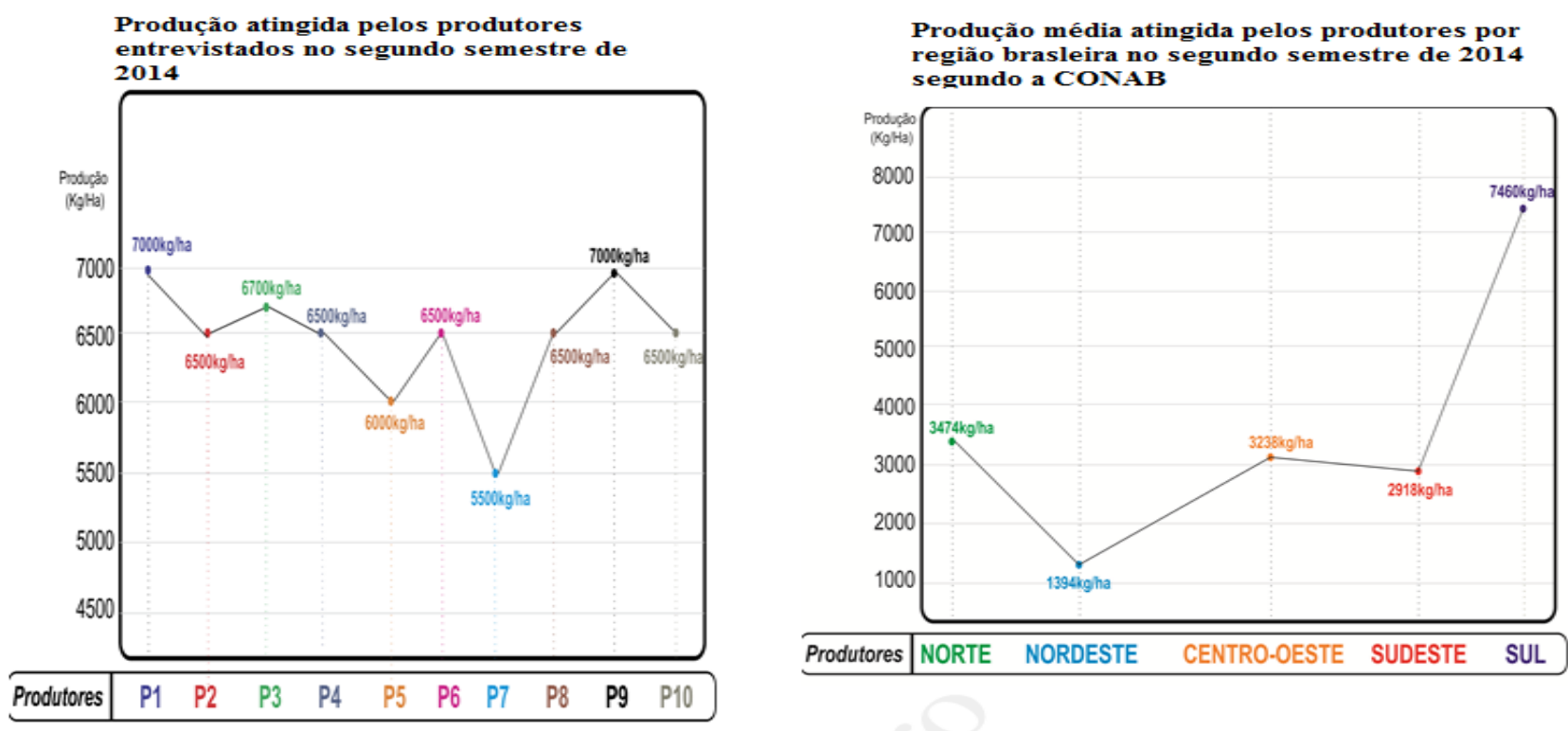

Figura 2. Produção obtida pelos entrevistados e a média das regiões brasileiras Fonte: Elaborado pelos autores (2015) com base nos dados coletados nas entrevistas e na CONAB.

Observa-se, pela Figura 2, que a região nordeste é a que menos produz arroz, por hectare, mas a cidade de Limoeiro, situada na região nordeste, tem produtividade superior a quase todas as regiões; só perde para a região sul.

Por meio da pesquisa, o total de custos do arrozal, a receita obtida e o resultado financeiro da operação encontram-se na Tabela 2 a seguir. 
Análise da Eficiência da Gestão de Custos do Processo de Produção de Arroz por pequenos e médios produtores de Limoeiro do Norte - CE

Geanne Benevides Sá Negreiros, Rosângela Venâncio Nunes Rosângela Venâncio Nunes, Charles Washington Costa de Assis, Alexandra Alencar Siebra, Rita de Cássia Fonseca

Tabela 2

Resultado \$ da Produção Arroz por hectare Safra - 2014.2

\begin{tabular}{clll}
\hline PRODUTOR & RECEITAS & GASTOS & RESULTADOS \\
\hline 01 & $\mathrm{R} \$ 5.250,00$ & $\mathrm{R} \$ 2045,00$ & $\mathrm{R} \$ 3.205,00$ \\
02 & $\mathrm{R} \$ 7.150,00$ & $\mathrm{R} \$ 2.624,32$ & $\mathrm{R} \$ 4.525,68$ \\
04 & $\mathrm{R} \$ 4.875,00$ & $\mathrm{R} \$ 2.587,50$ & $\mathrm{R} \$ 2.287,50$ \\
03 & $\mathrm{R} \$ 7.370,00$ & $\mathrm{R} \$ 2.636,50$ & $\mathrm{R} \$ 4.733,50$ \\
05 & $\mathrm{R} \$ 4.620,00$ & $\mathrm{R} \$ 2.640,75$ & $\mathrm{R} \$ 1.979,25$ \\
06 & $\mathrm{R} \$ 5.005,00$ & $\mathrm{R} \$ 1.916,50$ & $\mathrm{R} \$ 3.088,50$ \\
07 & $\mathrm{R} \$ 4.125,00$ & $\mathrm{R} \$ 1.933,50$ & $\mathrm{R} \$ 2.191,50$ \\
08 & $\mathrm{R} \$ 4.875,00$ & $\mathrm{R} \$ 2.272,50$ & $\mathrm{R} \$ 2.602,50$ \\
09 & $\mathrm{R} \$ 5.250,00$ & $\mathrm{R} \$ 2.536,00$ & $\mathrm{R} \$ 2.714,00$ \\
10 & $\mathrm{R} \$ 5.200,00$ & $\mathrm{R} \$ 2.350,00$ & $\mathrm{R} \$ 2.850,00$ \\
\hline
\end{tabular}

Nota. Fonte: Elaborado pelos autores (2015)

Observando monetariamente os dados coletados, por hectare, dois pequenos agricultores (P2 e P3) foram mais eficientes que os médios (P6 e P1) produtores. Ao final do processo, ocorreu um fato relevante que aumentou consideravelmente a eficiência econômica dos seguintes produtores: P2 e P3. Este fator está relacionado ao preço pago pelo produto ofertado. O arroz oferecido por P2 e P3 é do tipo vermelho, e o preço desta mercadoria é aproximadamente $35 \%$ superior ao tipo puitá, arroz branco, comercializado pelos demais produtores. O preço aproximado do arroz tipo branco é de $\mathrm{R} \$ 0,77$ o quilo; do tipo vermelho é de $\mathrm{R} \$ 1,10$ o quilo.

Avaliando o resultado financeiro, todos os agricultores investigados obtiveram lucro ao final do processo; nestas condições, todos foram eficientes. Mas o maior lucro foi do P3, e o menor foi do P5, apesar de os gastos serem idênticos. P1 e P6, médios produtores, tiveram lucros parecidos.

A Figura 3 apresenta a composição dos gastos, por hectare, em cada fase do cultivo nos custos totais de cada produtor. 
Análise da Eficiência da Gestão de Custos do Processo de Produção de Arroz por pequenos e médios produtores de Limoeiro do Norte - CE

Geanne Benevides Sá Negreiros, Rosângela Venâncio Nunes Rosângela Venâncio Nunes, Charles Washington Costa de Assis, Alexandra Alencar Siebra, Rita de Cássia Fonseca

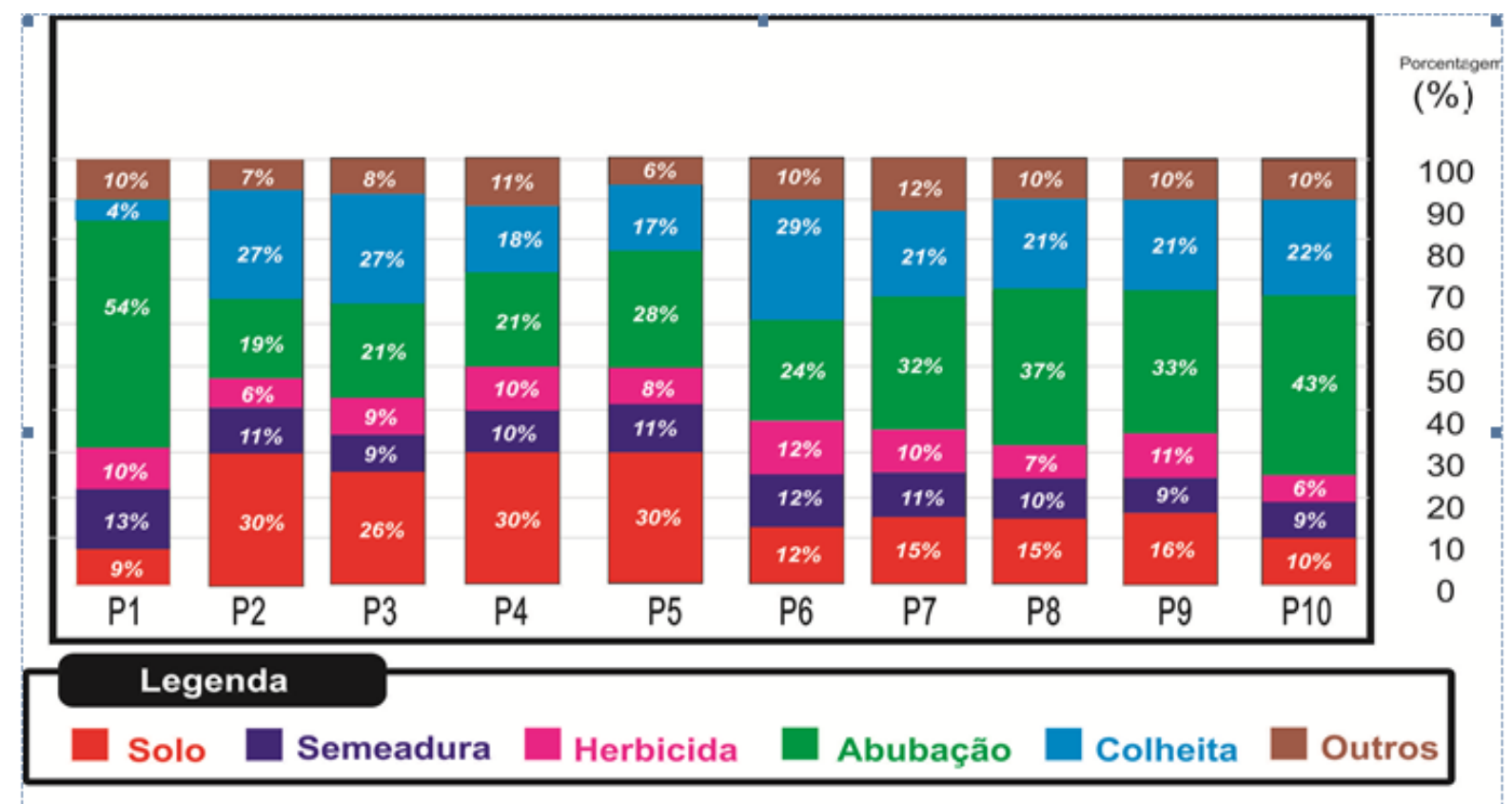

Figura 3. Composição dos gastos, por hectare, em cada fase do cultivo nos custos totais de cada produtor

Fonte: Elaborado pelos autores (2015).

Observando os dados da Figura 3, o arrendamento do terreno eleva materialmente o custo do pequeno produtor, sem terra, na primeira fase do cultivo. Outro fator relevante é o valor da operação, a mecanização terceirizada no preparo do solo. Excluindo P1 e P3, todos pagam pelo serviço, e foi constatado, pelos números, que o aumento é de, no mínimo, 30\% em relação aos gastos do $\mathrm{P} 1$, produtor com equipamento, que executa o serviço de forma particular. Observe-se no gráfico: só dois produtores gastaram com fundação: P1, de forma mecanizada, e o P10 de forma manual, mão de obra barata.

$\mathrm{Na}$ fase da semeadura, oito produtores optaram pelo grão do tipo puitá, dois escolheram o do tipo vermelho. O preço de compra de ambas é aproximado, mas na venda do arroz colhido, há uma diferença considerável de 35\%. P1 adquiriu sementes a $\mathrm{R} \$ 0,75$, praticamente $25 \%$ mais barato que para a maioria dos agricultores.

P2 e P5 utilizam 250 quilos de sementes, $25 \%$ a mais que os demais produtores. O primeiro prevê uma perda de $20 \%$ com sementes estragadas. 
Análise da Eficiência da Gestão de Custos do Processo de Produção de Arroz por pequenos e médios produtores de Limoeiro do Norte - CE

Geanne Benevides Sá Negreiros, Rosângela Venâncio Nunes Rosângela Venâncio Nunes, Charles Washington Costa de Assis, Alexandra Alencar Siebra, Rita de Cássia Fonseca

Nesta fase, P5, P7, P8, P9, P10 usaram mão de obra barata, praticamente pela metade do valor pago, se o serviço fosse terceirizado. Todos os agricultores, sem exceção, reclamaram dos custos com insumos, adubo e herbicida.

Os gastos com herbicidas são difíceis de controlar porque dependem de uma provável praga que pode se desenvolver de várias formas: lagarta, bicheiro da raiz, mancha-parda, dentre outras. Nesse período, P10 foi quem menos sofreu com esta ameaça. Já P9 precisou de mais herbicidas para combater a infestação.

$\mathrm{O}$ produtor $\mathrm{P} 10$ é quem mais gasta em adubo, depois do $\mathrm{P} 1$, e trabalha na mesma terra há mais de vinte anos. Aproximadamente $60 \%$ dos gastos do P1 são com adubação. É um registro bastante elevado se comparado com os demais. Quem menos investiu em adubo, dentre os produtores analisados, foi o P7: apenas $300 \mathrm{~kg}$; também foi quem menos produziu.

A maioria usou mão de obra barata. P3 e P1 fizeram o enxerto mecanizado e de forma particular. P2 e P4 terceirizaram o serviço e pagaram caro em relação ao serviço manual. Esta penúltima etapa, juntamente com a colheita, representam mais de $40 \%$ dos custos do pequeno produtor.

A colheita consome $10 \%$ da safra do arrozeiro cearense, ou seja, quanto maior for a produção, maior será o valor pago, elevando materialmente os custos dos agricultores, excluindo $\mathrm{P} 1$, que possui colheitadeira e apresentou custos com mão de obra barata e óleo; o mesmo disse que gastos com manutenção do equipamento eram irrelevantes.

Observando os custos de forma geral, mão de obra, energia e água são de baixo valor. Já o processo de adubação requer alto investimento, seja pequeno ou médio produtor. O arrendamento, a mecanização e a colheita têm um impacto substancial no lucro do pequeno investidor.

Na Figura 4, pode-se visualizar o nível de eficiência de cada produtor, conforme representação de eficiência dada por Padoveze (2005). 
Análise da Eficiência da Gestão de Custos do Processo de Produção de Arroz por pequenos e médios produtores de Limoeiro do Norte - CE Geanne Benevides Sá Negreiros, Rosângela Venâncio Nunes Rosângela Venâncio Nunes, Charles Washington Costa de Assis, Alexandra Alencar Siebra, Rita de Cássia Fonseca

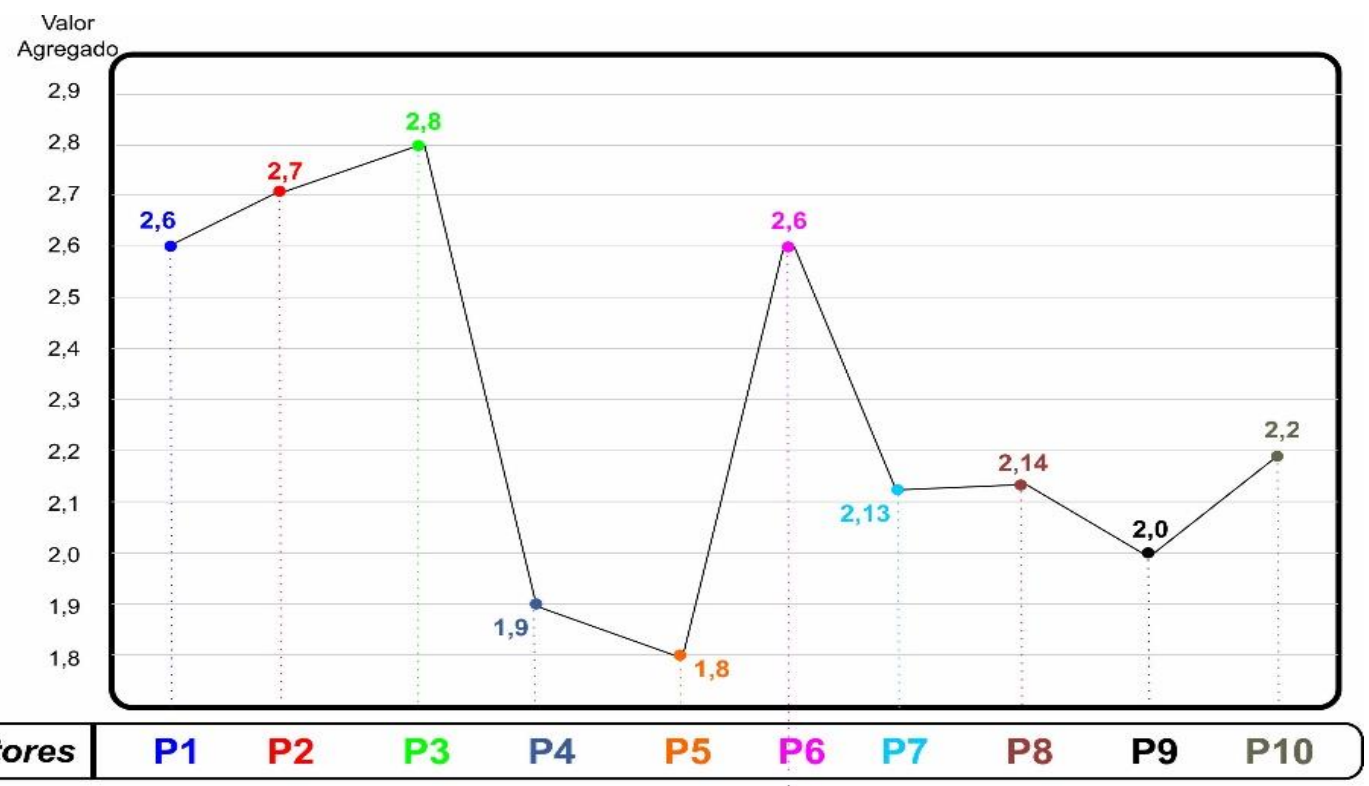

Figura 4. Eficiência obtida por produtor

Fonte: Elaborado pelos autores (2015).

Verificando a Figura 4, dentre os dez produtores investigados, pode-se observar que P3, pequeno produtor, foi mais eficiente. Os médios produtores obtiveram o mesmo nível de eficiência. Apesar de P1 possuir toda uma infraestrutura montada, o mesmo não conseguiu ser mais eficiente por causa da adubação.

O arroz oferecido pelos segundo e terceiro produtores foi mais valorizado no mercado, elevando materialmente o lucro. Em relação ao consumo de água, nenhum agricultor foi eficiente porque o próprio sistema requer o terreno encharcado em boa parte do processo. Estão surgindo novas tecnologias que diminuem o consumo de água, como a irrigação por gotejamento, mas ainda não chegou a Limoeiro.

Apesar do consumo exagerado de água, o sistema de irrigação trouxe maior segurança no plantio e aumentou a produção consideravelmente. Antes, havia uma só colheita e, com elevado risco de perda, o plantio dependia $100 \%$ da água da chuva.

Observando o aspecto econômico, herbicidas são bem vantajosos porque protegem a safra e garantem a renda do produtor. Mas, levando em consideração que 
Análise da Eficiência da Gestão de Custos do Processo de Produção de Arroz por pequenos e
médios produtores de Limoeiro do Norte - CE

Geanne Benevides Sá Negreiros, Rosângela Venâncio Nunes Rosângela Venâncio Nunes, Charles Washington Costa de Assis, Alexandra Alencar Siebra, Rita de Cássia Fonseca

herbicidas são tóxicos e que seu uso em excesso degrada o meio ambiente, é imprescindível um controle rigoroso na aplicação deste insumo. Assim, verificou-se que um agricultor trabalhou da melhor maneira cabível, mas, ao final da safra, teve prejuízo porque, na época da colheita, choveu. Apesar de todas as adversidades desta atividade, o planejamento, a organização e o controle são grandes aliados na realização de qualquer processo.

\section{CONSIDERAÇÕES FINAIS}

Verificou-se no estudo a complexidade de analisar a eficiência na agricultura, porque esta atividade possui especificidades inerentes ao seu processo natural de produção que nenhum outro setor da economia apresenta. São vários os fatores naturais que influenciam, de forma linear, o cultivo desde solo, chuva, praga, dentre outros fatores fora de controle do homem, como preço de insumos. É necessário um acompanhamento sistemático durante todo o ciclo produtivo, a observação do alinhamento e a composição do solo, o nível da água, a adubação de maneira adequada e o combate de pragas de forma correta. É necessário investir em tecnologia para reduzir custos, como na fase da colheita.

Observou-se no estudo que, após a implantação do sistema de irrigação por superfície, com disponibilidade de recursos hídricos provenientes do Rio Banabuiú, é possível ter duas safras ao ano, mesmo em período de seca, devido à tecnologia aplicada.

O presente estudo respondeu à indagação proposta, visto que se verificou que o nível de eficiência do processo produtivo de arroz realizado por pequenos e médios produtores localizados em Limoeiro do Norte, Ceará, é excelente quando comparado à produtividade dos mesmos em relação às regiões: norte, centro-oeste e sudeste.

Com relação ao pressuposto da pesquisa de que, ao se analisar o processo de produção e os custos de produção de arroz de pequenos e médios produtores localizados na cidade de Limoeiro do Norte, seriam constatados diferentes níveis de 
Análise da Eficiência da Gestão de Custos do Processo de Produção de Arroz por pequenos e
médios produtores de Limoeiro do Norte - CE

Geanne Benevides Sá Negreiros, Rosângela Venâncio Nunes Rosângela Venâncio Nunes, Charles Washington Costa de Assis, Alexandra Alencar Siebra, Rita de Cássia Fonseca

eficiência, verificou-se que, apesar das maiores dificuldades enfrentadas pelo pequeno produtor, na análise de dados, foi constatada uma pequena variação no nível de eficiência, por hectare, entre pequeno e médio produtor.

No decorrer do estudo, foi observado que a atividade agrícola é bastante complexa, pois fatores ambientais influenciam de forma direta na produção. Desse modo, é de vital relevância a realização de um acompanhamento diário durante todo o ciclo produtivo, observando estrutura do solo, nível de água e possíveis pragas que podem acabar com toda a produção. É também imprescindível um controle de gastos com insumos, visto que, na coleta de dados, foi constatado que mais de $40 \%$ dos gastos dos produtores correspondem aos insumos. Assim, a mecanização trouxe maior eficiência ao processo, mas também promoveu diversidades comerciais relevantes.

Cabe ressaltar que as conclusões obtidas só podem ser afirmadas para os produtores analisados; assim os resultados não podem ser generalizados, limitando, pois, o resultado das pesquisas.

Como sugestão para trabalhos futuros, sugere-se uma análise mais aprofundada do assunto com a utilização de uma amostra maior e com testes estatísticos. Outra sugestão cabível é analisar a gestão dos custos logísticos ou a gestão da cadeia de suprimentos desses pequenos e médios produtores.

\section{REFERÊNCIAS}

Antunes, G. M., Dias, M. F. P., \& Maehler, A. E. (2016). Processo de Inovação: Estudo de Caso da Adoção do Sistema de Produção de Arroz Orgânico Vinculada ao Nema. Revista de Administração da UFSM, 9(2), 262-279.

Associação Nacional de Pós-Graduação e Pesquisa em Administração, Enanpad. Rio de Janeiro, RJ, Brasil, 37. Recuperado de: http://www.anpad.org.br/admin/pdf/2013_EnANPAD_APB84.pdf

Barros, C. (2014). Ponto de encontro da cadeia produtiva de ovinos e caprinos. Recuperado de: < http://www.farmpoint.com.br/radarestecnicos/gerenciamento/comoreduzir-custo-de-producao-88272n.aspx> 


\section{Análise da Eficiência da Gestão de Custos do Processo de Produção de Arroz por pequenos e médios produtores de Limoeiro do Norte - CE}

Geanne Benevides Sá Negreiros, Rosângela Venâncio Nunes Rosângela Venâncio Nunes, Charles Washington Costa de Assis, Alexandra Alencar Siebra, Rita de Cássia Fonseca

Beutler, A. N., Centurion, J. F., Silva, A. D., Roque, C. G., \& Ferraz, M. V. (2004). Compactação do solo e intervalo hídrico ótimo na produtividade de arroz de sequeiro. Pesquisa Agropecuária Brasileira, 39(6), 575-580.

Breseghello, F., Rangel, P. H. N., \& Morais, O. P. (1999). Ganho de produtividade pelo melhoramento genético do arroz irrigado no Nordeste do Brasil. Pesquisa Agropecuária Brasileira, 34(3), 399-407.

Buzetti, S., Bazanini, G. C., Freitas, J. G., Andreotti, M.; Arf, O., Sá, E., Meira, F. A. (2006). Resposta de cultivares de arroz a doses de nitrogênio e do regulador de crescimento cloreto de clormequat. Pesquisa Agropecuária Brasileira, 41(12), 17311737.

Carvalho-Pupatto, J. G.,Büll, L. T.,Crusciol, C. A. C.,Mauad, M., \& Silva, R. D. (2003). Efeito de escória de alto forno no crescimento radicular e na produtividade de arroz. Pesquisa Agropecuária Brasileira, 38(11), 1323-1328

Castro, R. Eficácia, eficiência e efetividade na administração pública. Recuperado de: http://www.anpad.org.br/enanpad/2006/dwn/enanpad2006-apsa-1840.pdf

Cervo, A. L., Bervian, P. A. (2002). Metodologia científica (5a ed.). São Paulo: Prentice Hall.

Companhia Nacional de Abastecimento, CONAB. Sistemas de produção para arroz e feijão.Recuperado de: http://www.feis.unesp.br/Home/departamentos/fitotecniatecnologiadealimentosesoci oeconomia716/orivaldoarf/arroz-pg-2014---aula-01.pdf

Companhia Nacional de Abastecimento, CONAB. Perspectivas para a agropecuária.Recuperado de: http://www.conab.gov. br/OlalaCMS/uploads/arquivos/14_09_10_18_03_00_perspectivas_2014-15.pdf

Companhia Nacional de Abastecimento, CONAB. Custos da produção agrícola. Recuperado de:http://pt.slideshare.net/helidame squita/custos-produo-conab-1

Departamento Nacional de Obras Contra as Secas, DNOCS. Perímetro irrigado Jaguaribe-Apodi.Recuperado de: http://www.dnocs.gov .br/ dnocs /doc/canais/perimetros_irrigados/ce/jaguaribe_apodi.html

Diário do Nordeste (2011). Limoeiro também investe em agricultura irrigada. Recuperado de: http://diariodonordeste.verdesmares.com.br/cadernos/ negocios/limoeiro-do-norte-tambem-investe-em-agricultura-irrigada-1.277153 


\section{Análise da Eficiência da Gestão de Custos do Processo de Produção de Arroz por pequenos e médios produtores de Limoeiro do Norte - CE}

Geanne Benevides Sá Negreiros, Rosângela Venâncio Nunes Rosângela Venâncio Nunes, Charles Washington Costa de Assis, Alexandra Alencar Siebra, Rita de Cássia Fonseca

Empresa Brasileira de Pesquisa Agropecuária, EMBRAPA. (2005). Cultivo do arroz irrigado no Brasil.Recuperado de: http://sistemasdeproducao. cnptia.embrapa.br/FontesHTML/Arroz/ArrozIrrigadoBrasil/

Estatuto do Produtor Rural PLS 325/06. Brasil. Recuperado de: http://www.senado.gov.br/noticias/agencia/ quadros/qd_152.html

Food and Agriculture Organization. Organização das Nações Unidas para a Alimentação e a Agricultura, FAO. Recuperado de: http://www.fao.org.br

Freitas, B. Os sistemas agrícolas. (2014). Recuperado de: http://www.mundoeducacao.com/geografia/os-sistemas-agricolas.htm

Freitas, B. Departamento Nacional de Obras Contra as Secas, DNOCS. Dossiês perímetros irrigados. Disponível em : http://dossieperimetro sirrigados.net/estudosde-caso/perimetro-irrigado-jaguaribe-apodi/

Freitas, T. D., Silva, P. D., Mariot, C. H. P., Menezes, V. G., Anghinoni, I.,Bredemeier, C., \& Vieira, V. M. (2008). Produtividade de arroz irrigado e eficiência da adubação nitrogenada influenciadas pela época da semeadura. Revista Brasileira de Ciência do Solo, 32(6), 2397-2405

Instituto Brasileiro de Geografia e Estatística, IBGE. Cidades. Recuperado de: http://cidades.ibge.gov.br/xtras/perfil.php? codmun=230760

Kiss, J. (2015). A segunda onda. Revista Globo Rural. Recuperado de: http://revista globorural.globo.com/GloboRural/0,6993,EEC691085-2344,00.html

Lei 11.428/06. Recuperado de: http://www.planalto.gov.br/ccivil_03/_ato20042006/2006/lei/l11428.htm

Martins, P., Laugeni, A. (2012). Administração da produção fácil. São Paulo: Saraiva.

Ministério do Desenvolvimento Agrário. Secretaria da Agricultura Familiar. Manual do agente emissor de declaração de aptidão ao Pronaf. Recuperado de: http://www.mda.gov.br/sitemda/sites/sitemda/files/user_arquivos_64/MANUAL_DO_ AGENTE_EMISSOR_CORRE\%C3\%87\%C3\%95ES_16.01.2014_(1).pdf

Moreira, D. (2011). Administração da produção e operações. São Paulo: Pioneira.

Oliveira, M. F. de. (2011). Metodologia científica: um manual para a realização de pesquisas em administração.Recuperado de: https://adm.catalao. ufg.br/up/567/o/Manual_de_metodologia_científica_-_Prof_Maxwell.pdf 


\section{Análise da Eficiência da Gestão de Custos do Processo de Produção de Arroz por pequenos e médios produtores de Limoeiro do Norte - CE}

Geanne Benevides Sá Negreiros, Rosângela Venâncio Nunes Rosângela Venâncio Nunes, Charles Washington Costa de Assis, Alexandra Alencar Siebra, Rita de Cássia Fonseca

Padoveze, L. C. (2005).Controladoria. Estratégica e Operacional. São Paulo: Editora Thomson.

Pontes, P. A., Aragão. K. (2013, Setembro). Os Perímetros Irrigados do Ceará: Os Grandes Projetos de Irrigação têm Impacto Sobre a Renda Local? Anais do Encontro Nacional da Associação Nacional de Pós-Graduação e Pesquisa em Administração, Rio de Janeiro/RJ, Brasil, 37.

Resolução 4174/2012. Ministério da Agricultura, Pecuária e Abastecimento. Recuperado de: http://sistemasweb.agricultura.gov.br:/sislegis/action/detalhaAto.do?method= visualizarAtoPortalMapa\&chave $=1797518661$

Secretaria de Estado de Agricultura, Pecuária e Abastecimento. Perfil do Agronegócio brasileiro. Recuperado de: http://www.agricultura.mg. gov.br/images /files/perfil/perfil_brasil1.pdf

Sperotto, R. C. (2013). Federação da Agricultura do Estado do Rio Grande do Sul Praça, Farsul. Relatório Econômico 2013: perspectivas 2014. Recuperado de: http://www.farsul.org.br/arquivos/relatorio_2013.pdf

Santos, F. S. S. dos, Campos, K. C., Coelho, E. L., Silva, F. L. Da, \& Oliveira, V. R. De. (2014). Avaliação de perímetros públicos irrigados no Ceará. Revista Política Agrícola, Ano 23, n. 3, jul. / set. 2014. Recuperado de: < http:// www.agricultura.gov.br/arq_editor/RPA\%203\%202014.pdf>

Silva, O., \& Venanzi, D. (2013). Gerenciamento da produção e operações. São Paulo: Editora ABDR.

Slack, N., Chamber, S., \& Johnston, R. (2009). Administração da produção (3a. ed.). São Paulo: Atlas.

Souza, F., Barbosa, F. C.,Teixeira, A. S. Dos., \& Raimundo, N. T. C. (2006). Eficiência de irrigação em perímetros irrigados do estado do Ceará - Brasil. Recuperado de: http://ceer.isa.utl.pt/cyted/mexico2006/tema\%203/21_FSouza_Brazil.pdf

Souza, L. C., Lara, M. A. (2014). Metodologia científica para projetos de pesquisa. Nova Lima: Faculdades Milton Campos. Recuperado de: http://www.mcampos.br/ centroextensao/nupe/Metodologia\%20para\%20projetos\%20de\%20pesquisa.pdf

ScientificPeriodicals Eletronic Library. Repositório de artigos científicos. Disponível em: $<$ http://spell.org.br/> 
Análise da Eficiência da Gestão de Custos do Processo de Produção de Arroz por pequenos e médios produtores de Limoeiro do Norte - CE

Geanne Benevides Sá Negreiros, Rosângela Venâncio Nunes Rosângela Venâncio Nunes, Charles Washington Costa de Assis, Alexandra Alencar Siebra, Rita de Cássia Fonseca

Silveira, V. M., Antunes, G. M., \& Dias, M. F. P. (2012). Inovação em sistemas de produção de arroz orgânico no Rio Grande do Sul. Revista de Administração da UFSM, 5 (edição especial), 715-728.

Tejon, L. (2015). Quase o dobro do arroz produzido só com a metade da água da irrigação. Recuperado de: http://www.agriculturasustentavel.org.br/artigos/quase-odobro-do-arroz-produzido-so-com-a-metade-da-agua-na-irrigacao

Xavier, R., \& Abbade. E. B. (2016). Por que a produtividade do arroz uruguaio é maior que a do arroz brasileiro? Revista em Agronegócio e Meio Ambiente, Maringá (PR), v. $9, \quad$ n. $2, \quad$ p. 323-356. Recuperado de: http://periódicos.unicesumar.edu.br/index.php/rama/article/viewFile/3738/2779

Data de Submissão: 24/05/2016

Data de Aceite: 16/08/2017 